\title{
Cardiac Catheterization Laboratory
}

National Cancer Institute

\section{Source}

National Cancer Institute. Cardiac Catheterization Laboratory. NCI Thesaurus. Code C51965.

An establishment staffed, equipped, and licensed for performing invasive and noninvasive cardiovascular procedures (e.g. diagnostic heart catheterization, selective coronary ang iography and graft ang iog raphy, ang io plasty, stent placement, endomyocaridal biopsy, valvuloplasty, etc.) used to diagnose and treat various cardiac and circulatory diseases. Cardiac catheterization laboratory may either be part of a hospital, affiliated with a hospital, or exist as a free-standing facility. 